\author{
Manuscript submitted to \\ Advances in Structural Engineering - An International Journal \\ (Special Issue)
}

\title{
DEVELOPMENT OF STRUT-AND-TIE MODELS IN DEEP BEAMS WITH WEB OPENINGS
}

by

\section{Hong Guan, Jeung-Hwan Doh}




\title{
DEVELOPMENT OF STRUT-AND-TIE MODELS IN DEEP BEAMS WITH WEB OPENINGS
}

\author{
Hong Guan*, Jeung-Hwan Doh \\ Griffith School of Engineering, Griffith University Gold Coast Campus, PMB50 Gold Coast Mail Centre, \\ Queensland, Australia
}

\begin{abstract}
The strut-and-tie models of a total of fourteen (14) concrete deep beams with varying size and location of web openings are developed herein using a topology optimisation approach. By systematically eliminating inefficient materials from an over-designed discretized domain, the load transfer mechanism in deep beams is progressively characterised by the residual part of the structure. Both von Mises stress and displacement sensitivity number are used as deletion criteria with the aim of maximising the material efficiency and overall stiffness of the structural beam. The performance indices in terms of von Mises stress and nodal displacement are evaluated to monitor the optimisation process and to determine the optimal topology which is transformed to the strut-and-tie model. The relationship between the strut-and-tie models and the ultimate load-carrying capacity of the beams are discussed in some detail. A series of comparisons offer insight into the varying characteristics of the strut-and-tie models influenced by the size and location of web openings. To demonstrate the effectiveness of the resulting strut-and-tie model in aiding the
\end{abstract}

\footnotetext{
* Corresponding author. Tel.: +61 75552 8708; fax: +61 755528065.

E-mail address: h.guan@griffith.edu.au
} 
design of deep beams, a worked design example of a representative beam is also presented where the practical layout of main steel reinforcement is determined.

Keywords: Concrete deep beams; strut-and-tie model; web openings; topology optimisation; design.

\section{Introduction}

A deep beam is defined as a beam having a depth $(D)$ comparable to the span length $(L)$, $L / D<5$. Deep beams demonstrate non-flexural behaviour and are considered as discontinuity regions because the sectional strain distribution deviates from linearity. Deep beams cannot be designed as standard beams using common design methods as the assumptions in beam theory (linear sectional strain distribution) become invalid.

In recent years, concrete wall/deep beam interconnecting systems in tall-building and precast construction have become increasingly popular worldwide. This is because there is a huge demand for structures to be built to high elevations due to the lack of land available, especially in major modern cities. Although reinforced concrete deep beams are of considerable interest in structural engineering practice, the major codes of practice (AS3600 2002; ACI318-05 2005; CSA 1984; CIRIA 1977) still offer little guidance for the design of deep beams in particular when openings in the web region are provided for essential services and accessibility (Kong 1990). The need for an accurate design methodology for deep beams with openings is becoming increasingly necessary with the subsequent growth in the use of deep beams in construction industry. 
The inclusion of openings in a deep beam significantly affects its structural behaviour as demonstrated in the existing literature on the effects of web openings in deep beams (Kong and Sharp 1977; Kong et al. 1978; Mansur and Alwis 1984; Ray 1990; Almeida and Pinto 1999; Ashour and Rishi 2000; Maxwell and Breen 2000; Tan et al. 2003). A simple structural idealization for predicting the ultimate shear strength of deep beams with web openings was proposed some thirty years ago based on a series of laboratory testing conducted by Kong and Sharp (1977) and Kong et al. (1978). The structural idealization shows the lower and upper paths of load transfer when a web opening is present. It offers a good indication of the ultimate load-carrying capacity of the beam which is affected by the size and location at which the natural load path is interrupted by an opening. The internal forces in the discontinuity regions of a deep beam are represented by compressive concrete struts tied together by tensile ties (the reinforcement) which together act like a truss carrying the imposed loading through the region to the supports. One of the main advantages of using trusses to represent key resisting elements of a member is that the flow of forces can be easily visualised by the designer. Siao (1995) also suggested that the strut-and-tie could be used for the analysis of shear strengths of deep beams with web opening.

Topology optimisation of structures has increasingly gained popularity in recent year as it has been proven to significantly improve the efficiency of a design. The aim of topology optimisation is to find a conceptual layout of a design by distributing a given amount of material in a domain thereby achieving the lightest and stiffest structure while satisfying certain specified design constraints. There exist two distinctive methods for automatic generation of the strut-and-tie models based on the topology optimisation concept, namely the optimisation of a ground truss (Ali and White 2001; Biondini et al. 2001) and optimisation of a continuum structures (Liang et al. 2000, Liang 2005; Guan 2005). In the topological 
optimization of a ground truss, all possible joints and members connecting them are present in the initial model. The method is comprehensive in that multiple optimal solutions (strut-andtie models) can be generated to account for either serviceability or practicality considerations (Ali and White 2001). It can also yield reliable strut-and-tie models which better complies with the stress flow associated with a given structural element rather than just a classical minimum volume solution (Biondini et al. 2001). However, the optimal solutions generated from a ground truss are dependant on the assumed number and location of the joints hence the number and orientation of the members which eventually governs the inclination of reinforcement. On the other hand, the optimal topology of a plane stress continuum structure is not affected by a predetermined shape (joints and members) although it is usually trussliked. The element removal criteria are applied to an over-designed initial continuum domain. By systematically removing underutilised (lowly stressed) elements, an optimal topology (strut-and-tie model) can be generated. Although the method does not produce quantitatively the exact dimensions for each member, the location of struts, ties and nodes are indicated which will aid detailed design of a structural member. Due to its clear concept and easy mathematical operation, the Evolutionary Structural Optimisation (ESO) method is used in this study to automatically generate the strut-and-tie models of deep beams with web openings.

In this study, the strut-and-tie models of a total of fourteen (14) concrete deep beams with varying size and location of web openings, tested previously by Kong and Sharp (1977), are developed using the ESO approach. The relationship between the strut-and-tie models and the ultimate load-carrying capacity of the beams are discussed in some detail. To demonstrate the effectiveness of the resulting strut-and-tie model in aiding the design of deep 
beams, a worked design example of a representative beam is also presented following the design procedure adopted by Liang (2005) in the design and detailing of solid deep beams.

\section{Optimisation approach}

The strut-and-tie models are widely used to represent the load transfer mechanism in a cracked concrete member at the ultimate load. This is further supported by the fact that the strut-and-tie model representing a truss analogy normally assumes that after cracking the behaviour of a concrete beam becomes analogous to that of a truss. Based on an accurate load transfer mechanism, the structural member can be reinforced to achieve its maximum load carrying capacity. It is obvious that some portions of the structural member do not contribute efficiently to load carrying due to their low stress levels. These underutilised portions can then be eliminated gradually leading to a fully stressed and stiffest structural member representing a fully cracked stage at the optimum (Liang et al. 2000). In this study the development of the strut-and-tie model of deep beams with openings is transformed to a topology optimisation problem of continuum structures. The objective of such optimisation is to maximise the material efficiency and overall stiffness of an initial continuum design domain representing a deep beam. This is achieved by gradually eliminating, from a discretized deep beam model, a small number of elements with lowest von Mises stress and lowest displacement sensitivity number. This ensures that the optimal topology is a fully stressed design and accurately represents the actual stress path and the load transfer mechanism. In the study, a

plain concrete beam is analysed assuming homogeneous continuum behaviour and a linear elastic behaviour of cracked concrete is also assumed. 
Following a finite element analysis of a deep beam model discretized into four-node plane stress elements, a deletion criterion is determined by multiplying the rejection ratio $R R_{i}$ and the maximum von Mises stress of the model, $\sigma_{v M \text {,max }}$. This criterion refers to a stress level at which all elements with a lower stress are deemed insignificant. As a result, an element is identified at the $i$ th iteration if its von Mises stress $\sigma_{v M}^{e}$ is less than the deletion criterion (Xie and Steven 1997). Or

$$
\sigma_{v M}^{e} \leq R R_{i} \times \sigma_{v M, \max }
$$

A small value of $R R_{i}(0.1-0.2 \%)$ should be used to ensure that only a small number $\left(N_{s}\right)$ of lowly stressed elements are identified at each iteration.

As stated by Liang (2005), topology optimisation based on the element removal concept is a design problem of maximizing the performance of a continuum structure in terms of the efficiency of material usage in resisting deformations. In the development of the strut-and-tie models, the least deformation of a deep beam must be sought at fully cracked stage because concrete can only sustain limited plastic deformations. This implies that when the lowly stressed material is eliminated, the remaining part of the beam must sustain adequate stiffness and its maximum deflection must be within a satisfactory limit. The optimisation process is terminated when the specified displacement limit is reached. Assuming that the nodal displacement at a specific location for example the $j$ th displacement component $u_{j}$ is to be limited to a prescribed value $u_{j}^{*}$, i.e. $\left|u_{j}\right| \leq u_{j}^{*}$. The displacement sensitivity number $\alpha_{d, i}$ indicating the variation in $u_{j}$ due to the elimination of the $i$ th element $(i=1, N$, where $N$ is the total number of elements in the design domain) can then be defined as (Guan 2005) 


$$
\alpha_{d, i}=\sum_{k=1}^{L} \sum_{j=1}^{M} \lambda_{j k} \cdot\left|\left\{\boldsymbol{u}_{i j}\right\} \mathrm{T} \cdot\left[\boldsymbol{K}_{i}\right] \cdot\left\{\boldsymbol{u}_{i k}\right\}\right|
$$

where $\left\{\boldsymbol{u}_{i k}\right\}$ and $\left\{\boldsymbol{u}_{i j}\right\}$ are the displacement vectors of the $i$ th element due to real load case $k$ and virtual unit load at node $j$, respectively; $\left[\boldsymbol{K}_{i}\right]$ is the stiffness matrix of the $i$ th element; $L$ and $M$ are respectively the total numbers of load cases and displacement constraints; $\lambda_{j k}$ is the weighting parameter which is a function of the prescribed displacement value. In the optimisation process, $\alpha_{d, i}$ is calculated for a total number of $N_{s}$ elements that satisfy the stress condition as specified in Eqn 1. To minimise the displacement variation, a number of elements $N_{d}$ with the lowest $\alpha_{d, i}$ are eliminated. In this study, $N_{d}=$ the lesser of $N_{s}$ and 10, has shown to produce satisfactory results.

The finite element analysis followed by systematic elimination of lowly stressed and less displacement sensitive elements forms an optimisation cycle where $R R_{i}$ remains constant. Such cycle or iteration is continued until no more elements are eliminated. To proceed to the next iteration, $R R_{i}$ is increased by adding the evolution ratio $E R$. The repeated cycle of optimisation process continues until a desired topology is obtained.

As the optimisation cycle continues, the material efficiency and overall stiffness of the progressive topology improves. To identify the optimal topology, two performance indices $P I_{v M}$ (in terms of von Mises stress) and $P I_{d}$ (in terms of the nodal displacement) are examined according to the following two formulas based on the scaling design concept (Liang et al. 2000) 


$$
P I_{v M}=\left(\sigma_{v M, \max }\right)_{o} V_{o} /\left(\sigma_{v M, \max }\right)_{i} V_{i}
$$

and

$$
P I_{d}=u_{o} V_{o} / u_{i} V_{i}
$$

where $u$ is the nodal displacement at the location where the prescribed limit is imposed; $V$ is the volume of the design domain; and subscripts $o$ and $i$ denote the original stage and the $i$ th iteration, respectively. The vaules of $P I_{v M}$ and $P I_{d}$ of the initial design domain are both equal to unity. As the optimisation process continues, both $P I_{v M}$ and $P I_{d}$ increase, until a certain stage where the efficiency/stiffness of the topology deteriorates. The first reached maximum value of $P I_{v M}$ or $P I_{d}$ before declining corresponds to the most efficient and optimal topology, which can be transformed to the strut-and-tie layout for a deep beam model. In this study, the displacement constraint is applied to those elements that satisfy the stress constraint, hence the displacement sensitivity number governs the progressive topologies. It is found that for all the cases studied herein, $P I_{d}$ always first reach the maximum value which governs the optimal topology. This further indicates that the index for displacement is capable of measuring the performance of a structural topology in terms of the efficiency of material usage in resisting deformations. It should be noted that the optimal topology corresponding to the maximum $P I_{d}$ is unique for any prescribed displacement limit.

\section{Deep beams with web openings}

A total of 14 simply support deep beams tested previously by Kong and Sharp (1977) are optimised herein to produce the strut-and-tie models reflecting varying size and location of web openings. All the beams have the same dimension with the overall depth $D$ of $750 \mathrm{~mm}$, the span length $L$ of $1125 \mathrm{~mm}$ between the centre lines of the two supports, the clear shear span $x$ 
of $225 \mathrm{~mm}$ and the breath $b$ of $100 \mathrm{~mm}$. This makes the span to depth ratio $L / D$ of 1.5 and the shear span to depth ratio $x / D$ of 0.3 , as presented in Figure 1(a). The variation of the size and location of the web openings is also illustrated in the figure with more detailed information given in Tables 1 and 2 in which results are summarised. Further the variation of the opening size and location is identified by reference numbers ranging from 1 to 4 and 7 to 16 . A typical designation for beam $\mathrm{O}-0.3 / 1$ indicates that the beam has no web reinforcement $(\mathrm{O})$, the shear span to depth ratio $x / D$ is 0.3 and the reference number of the web opening is 1 . The opening size is stipulated as $a_{1} x \times a_{2} D$, where the height factor $a_{2}$ of 0.2 is kept constant but the breadth factor $a_{1}$ varies from 0.3 to 1.3 . The opening location is represented by $k_{1} x$ and $k_{2} D$. All the beams are subjected to two symmetrically applied concentrated loads. Steel bearing blocks of $100 \times 100 \times 30 \mathrm{~mm}$ are placed at both loading and the support locations. The cylinder compressive strengths of concrete for all the 14 beams are given in Kong and Sharp (1977). Due to symmetry, only half of each beam is analysed with Quad-4 plane stress elements. The Young's modulus $E=28,567 \mathrm{MPa}$ and Poisson's ratio $v=0.15$ are specified for the concrete material. In the optimisation process, both $R R_{i}$ and $E R$ are taken as $0.1 \%$ to ensure that only a small number of elements are eliminated at each iteration. In addition, a local refinement around the opening is often necessary to minimize checkerboard patterns (Reynolds et al. 2001). The optimisation histories, the optimal topologies and the comparisons between the strut-and-tie models with the experimental crack patterns are presented for a representative deep beam. The discussion on the strut-and-tie model is mainly based on the structural idealisation suggested by Kong and Sharp (1977), as illustrated in Figure 1(b). 


\section{Development of the strut-and-tie models}

\subsection{Optimal strut-and-tie model}

For all the 14 deep beam models, topology optimisation is performed where the progressive topologies are recorded for each beam at typical percentages of volume reduction. Figures 2(a) to (e) present the development of the strut-and-tie model for deep beam O-0.3/16. The optimal topology is determined at iteration 388 when $P I_{d}$ first reaches maximum before declining takes place, as indicated in Figure 2(f). This topology can then be transformed to the strut-and-tie model (Figure 2(g)) where solid lines indicate the tensile ties and the dash lines denote the compressive struts. The experimental crack pattern shown in Figure 2(h) compares favourably with the strut-and-tie model. The two major diagonal shear cracks (along the lower path ABC as indicated in Figure 1(b)) were developed from the corners of the opening to the loaded area and the closest support. This suggests that the top and bottom areas of the opening are under high tensile stresses. Also noticed are a number of flexural cracking at the bottom of the beam. Hence it is necessary to provide steel reinforcement in these locations to counteract the low tensile capacity of concrete. The tension ties formed in the strut-and-tie model clearly correspond to these locations which validates the correctness of the model developed.

\subsection{Influence of the size of openings}

Table 1 presents the strut-and-tie models influenced by the size of web openings. In Table 1(a), the opening of the same height is located at the mid-depth of each of the four beams $(\mathrm{O}-0.3 / 7,8,9,10)$ as $a_{2}$ and $k_{2}$ are kept constant as 0.2 and 0.4 , respectively. The 
opening width varies with the left side of the opening in line with the interior support point. As such, angle $\emptyset^{\prime}$ (see Figure 1(b)) and hence the efficiencies of the upper path are identical for all the four beams. With an increase in the width factor $a_{1}$ from 0.3 to 1.3 , the lower path angle $\varnothing$ progressively decreases which in turn reduces the effectiveness of the lower (main) load path of the beam. This can be further confirmed by the reduced ultimate shear strength of the four beams (from $420 \mathrm{kN}$ to $210 \mathrm{kN}$ ) as specified also in Table 1(a). In general, the compression struts appear in the positions corresponding to the upper and lower paths of the structural idealization, as shown in Figure 1(b). As seen in Table 1(a), the upper and lower compression transfers generate from the loading point, before enveloping the opening and extending down to the support point. The tension ties are introduced connecting the compression zones above and below the opening. Also, when the opening becomes wider as seen in $\mathrm{O}-0.3 / 9$ and $\mathrm{O}-0.3 / 10$, the strut-and-tie model becomes more complicated and the bottom tension tie is interrupted by the lower compression transfer. In addition, instead of forming a horizontal tie in the bottom when the opening is small in size $(\mathrm{O}-0.3 / 7$ and $\mathrm{O}$ 0.3/8), the tension tie in $0-0.3 / 9$ starts to bend upwards and finally in $\mathrm{O}-0.3 / 10$ merges with the tie below the opening. Further, an additional vertical strut forms below the lower compression transfer in O-0.3/9 and O-0.3/10.

Table 1(b) offers more evidences about the influence of opening size on the characteristics of the strut-and-tie models. Four beams $(\mathrm{O}-0.3 / 12,13,15,16)$ are divided into two pairs. In each pair, two beams, having the same depth $\left(a_{2}=0.2\right)$ but different width $\left(a_{1}=\right.$ 0.3 and 1.0) of openings, are located at the same location, viz. in the upper region of beams $\mathrm{O}-0.3 / 12$ and $\mathrm{O}-0.3 / 13\left(k_{2}=0.667\right)$ and in the lower region of $\mathrm{O}-0.3 / 15$ and $\mathrm{O}-0.3 / 16\left(k_{2}=\right.$ 0.134). In all the four beams, the left side of the opening coincides with the line of interior support point. 
In the first pair, the strut-and-tie models are more or less the same though the opening widths are fairly different. When the opening width is very small $(\mathrm{O}-0.3 / 12)$ and does not falls in the load transfer path, the compression transfer takes the shortest, natural load path from the loaded area to the support which is similar to the beam without an opening. The ultimate load $(560 \mathrm{kN})$ of $\mathrm{O}-0.3 / 12$ is also almost equal to that of the beam without an opening (595 kN) (Kong et al. 1978). In O-0.3/13, the opening falls in the load path and the connecting point of the three struts is moved down to the bottom corner of the web opening. The upper load path is secondary and gradually vanishes during the optimisation process due to the small upper path angle $\varnothing^{\prime}$. This is a major difference from O-0.3/12.

For the second pair, the opening in the two beams falls in the load path (Table 1(b)). With a small opening in $\mathrm{O}-0.3 / 15$, the strut-and-tie model becomes relatively simple as the compression transfers run directly from the loading point enveloping the opening to the support. With a wider opening in O-0.3/16, the lower compression transfer is interrupted. There also forms an additional horizontal tie between the left and right openings joining both the left and right lower compression transfers. The upper path angles $\emptyset^{\prime}$ are identical for these two beams whereas the lower path angle $ø$ is smaller in O-0.3/16 resulting in a reduced loadcarrying capacity (195 kN) as compared to its counterpart O-0.3/15 (260 kN).

\subsection{Influence of the location of openings}

Table 2 examines the characteristics of the strut-and-tie models with the variation of the opening location. Table 2(a) demonstrates the strut-and-tie models on six beams (O-0.3/11, 12, $1,7,14,15)$ with constant size factors $a_{1}=0.3$ and $a_{2}=0.2$. The vertical locations of the 
opening vary from the top to the bottom of the beams $\left(k_{2}=0.667,0.4\right.$ and 0.134$)$ and the horizontal locations vary from adjacent to the loaded area to the support point $\left(\left(k_{1}=1.0\right.\right.$ and 0.3). The strut-and-tie mode for O-0.3/1 consists of an additional vertical strut stretching from the lower compression path straight to the bottom horizontal tie which eventually bends up to join the two struts above the support point. Compared to the remaining five beams, O-0.3/1 has only its upper strut converges to the support point. When the opening shifts horizontally leftward away from the load path as in O-0.3/7, the strut-and-tie model becomes much simpler. When the opening is very close to the loaded area as in O-0.3/11, an unusual strut-and-tie layout evolves. Instead of two, only a single tie connecting the upper and lower compression transfers is generated under the opening and an additional short strut is observed above the opening connecting the starting point of the two standard struts. The bottom horizontal tie forms similarly in $\mathrm{O}-0.3 / 11$ as compared to $\mathrm{O}-0.3 / 1$ because of the same horizontal location of the opening in the two beams. When the opening is reasonably away from the load path (as in O0.3/12 and O-0.3/14), the compression transfer takes the shortest path from the loading point to the closest support which resembles well to that of the beam without an opening. When the opening is located close to the beam soffit as in $\mathrm{O}-0.3 / 15$, the strut-and-tie model shows a standard pattern apart from the horizontal tie directly connecting the lower tie below the opening.

A total of seven beams $(\mathrm{O}-0.3 / 2,8,3,9,13,4,16)$ as presented in Table 2(b) are divided in to three groups. In each group, the beams contain an opening of the same size. The first two groups (O-0.3/2 vs. O-0.3/8 and $\mathrm{O}-0.3 / 3$ vs. O-0.3/9) represent the openings located at the same vertical location (at mid-depth, $k_{2}=0.4$ ) but different horizontal location (adjacent to the left or right boundaries of the clear shear span, $k_{1}=1.0,0.5$ and 0.7$)$. The third group deals with three beams $(\mathrm{O}-0.3 / 13, \mathrm{O}-0.3 / 4$ and $\mathrm{O}-0.3 / 16)$ with the opening size equivalent to the clear shear span 
$\left(a_{1}=1.0, a_{2}=0.2\right)$ and with varying locations vertically (near the top $k_{2}=0.667$, at mid-depth $k_{2}=0.4$, and near the bottom $k_{2}=0.134$ of the beam respectively).

In the first group, the arrangement of struts and ties in $0-0.3 / 2$ and $0-0.3 / 8$ are very similar to that in $\mathrm{O}-0.3 / 1$ and $\mathrm{O}-0.3 / 7$, respectively, when the opening shifts from the right boundary of the clear shear span to the left. Such a shift increases the upper path angle $\varnothing^{\prime}$ and reduces the lower path angle $\varnothing$ in $\mathrm{O}-0.3 / 2$ as compared to those in $\mathrm{O}-0.3 / 8$. With a reduction in $ø$ of the main load path, O-0.3/2 is expected to resist lesser ultimate load. However, Table 2(b) shows that the load-carrying capacity of $\mathrm{O}-0.3 / 2$ is $10 \mathrm{kN}$ greater than that of $\mathrm{O}-0.3 / 8$.

The second group also deals with a similar case as group one except that the opening size in $0-0.3 / 3$ and $0-0.3 / 9$ is larger than that in $0-0.3 / 2$ and $0-0.3 / 8$. The strut-and-tie models for the two beams are relatively similar. The only dissimilarity is that in $\mathrm{O}-0.3 / 3$, only the upper compression transfer converges to the support point whereas in O-0.3/9 both the upper and lower compression transfers extend downward to the support. Considering the combine effect of the opening size and location in these two beams, little difference exists between their upper and lower path angles, $\varnothing^{\prime}$ and $ø$, hence the load-carrying capacities of the two beams should be similar which is supported by the identical ultimate load of $280 \mathrm{kN}$ as indicated in Table 2(b).

In the last group where the opening size is equivalent to the clear shear span, the configuration of the struts and ties distinctly differs with the alteration of the vertical location of the opening. The characteristics of the strut-and-tie model for O-0.3/13 and O-0.3/16 have been discussed earlier in Table 1(b). For O-0.3/4 where the opening is located at the middepth of the beam, an additional vertical strut is formed connecting the lower compression 
transfer and the bottom horizontal tie which appears to bend upwards to form the lower tie below the opening. The ultimate load-carrying capacity of the beam is very much affected by the vertical location of the opening. As seen in Table 2(b), the ultimate load of O-0.3/13 is $300 \mathrm{kN}$ when the opening intercepts the load path near the top of the beam. The ultimate load of $\mathrm{O}-0.3 / 4$ is reduced to $260 \mathrm{kN}$ when such an interception occurs at the mid-depth of the beam. When the interception occurred near the beam soffit as in $\mathrm{O}-0.3 / 16$, the ultimate load is reduced further to $195 \mathrm{kN}$. It is obvious from Figure 1(b) that the position of point B, which is crucial for the primary compression transfer path, is dependent on the vertical location of the opening. The lower the point $\mathrm{B}$, the smaller the angle $ø$, hence the lower the load-carrying capacity of the beam.

\section{Worked design example}

\subsection{Design procedure}

The strut-and-tie model developed using the optimisation technique represents the actual stress path and load transfer mechanism in a concrete deep beam under ultimate load. The model clearly indicates the locations of struts, ties and nodal zones in a deep beam. On the basis of this, a detailed design of the beam can be conducted and the load-carrying capacity as well as the failure characteristics of the deep beam can be accurately predicted. Following the specifications outlined in ACI 318-02 (2002), Liang (2005) successfully performed the design and detailing of two solid concrete deep beams based on the optimal strut-and-tie model developed using the performance-based optimisation approach. In this paper, a similar procedure is adopted for the design and dimensioning of a representative deep beam with web openings. Reproduced in Figure 3 is the strut-and-tie model for beam O- 
0.3/16 where the calculated axial forces in struts and ties are also indicated. The nodal zones are numbered in the figure as well. Due to symmetry, only half of the beam needs to be considered in the design. The design procedure is presented in Figure 4 in a form of a flow chart.

The strut and tie model approach is incorporated in ACI 318-05 (2005) for the design and detailing of non-flexural members or disturbed regions in a concrete structure. In the code, the effective compressive strength of concrete in struts is determined by

$$
f_{c u}=0.85 \beta_{s} f_{c}^{\prime}
$$

where $\beta_{s}=1$ for prismatic struts in compression zones; 0.75 for bottle-shaped struts with crack control reinforcement; 0.6 for bottle-shaped struts without crack control reinforcement; 0.4 for struts in tension members and all other cases.

ACI 318-05 also specifies the effective compressive strength of concrete in the boundaries of nodal zones as follows

$$
f_{c u}=0.85 \beta_{n} f_{c}^{\prime}
$$

where $\beta_{n}=1$ for nodal zones bounded by struts and/or bearing areas; 0.8 for nodal zones anchoring only one tie and 0.6 for nodal zones anchoring tension ties in more than one directions. 


\subsection{Bearing capacity of loading point}

The loading point (Point 4 in Figure 3) is bounded by three struts and a bearing plate, therefore $\beta_{n}$ is taken as 1.0. According to ACI 318-05, the bearing strength at the loading point can be determined as

$$
\phi F_{u n}=\phi 0.85 f_{c}^{\prime} \beta_{n} A_{n}
$$

where $\phi$ is the strength reduction factor is taken as 0.75 (ACI 318-05 2005); the concrete compressive strength $f_{c}$ ' is $37.6 \mathrm{MPa}$ as indicated in Kong and Sharp (1997), and $A_{n}$ is the area of the nodal zone face on which the axial force acts, and is equal to $100 \times 100 \mathrm{~mm}$. Hence $\phi F_{u n}=0.75 \times 0.85 \times 37.6 \times 1 \times 100 \times 100=239.7 \mathrm{kN}$ and is greater than the applied load $(=97.5$ $\mathrm{kN})$. Therefore, the bearing capacity of the loading point is adequate.

\subsection{Bearing capacity of support}

The nodal zone (Point 1 ) at the support anchors only one tie, $\beta_{n}$ is thus taken as 0.8 . The bearing strength at the support is $\phi F_{u n}=0.75 \times 0.85 \times 37.5 \times 0.8 \times 100 \times 100=191.8 \mathrm{kN}$ and is greater than the reaction force $(=92.9 \mathrm{kN})$. Therefore the bearing capacity of the supports is also adequate. 


\subsection{Capacity of struts}

The capacity of struts must also be checked according to ACI 318-05. For strut 1-2, as one of bottle-shaped strut members, the factor $\beta_{s}$ is taken as 0.6 without providing crack control reinforcement. The depth of the strut can be determined as

$$
d_{\text {strut }}=l_{b} \sin \theta+d_{a} \cos \theta
$$

where $l_{b}$ is the width of the bearing plate which equals $100 \mathrm{~mm}, d_{a}$ is the depth of the tie (in this case tie 1-3) and $\theta$ is the inclination angle of the strut. Based on the optimal topology presented in Figure 2(e), $d_{a}$ can be approximated as $50 \mathrm{~mm}$. Hence $d_{\text {strut }}=100 \sin 66.5^{\circ}+50 \cos 66.5^{\circ}=111.64 \mathrm{~mm}$. The capacity of struts is determined as

$$
\phi F_{u s}=\phi 0.85 f_{c}^{\prime} \beta_{s} A_{c}
$$

where $A_{c}=d_{\text {strut }} \times b$. The capacity of strut 1-2 can then be calculated as $\phi F_{u s}=\phi 0.85 f_{c}^{\prime} \beta_{s} A_{c}=0.75 \times 0.85 \times 37.6 \times 0.6 \times 111.64 \times 100=160.6 \mathrm{kN}$ and is greater than the corresponding axial force of the member $(=92.9 \mathrm{kN})$. Therefore, the capacity of strut $1-2$ is adequate. Table 3 summarises the capacities of all the struts in O-0.3/16. Also included in the table are the characteristics of each strut and other necessary data leading to the calculation of the strut capacity. Comparison with the corresponding compressive force in each strut indicates that all strut capacities are adequate and the crack control reinforcements are not required. 


\subsection{Capacity of nodal zones}

Using Eqn 7, the capacity of all 5 nodal zones can be determined. Note that $A_{n}$ is the effective cross-sectional area of strut. Summary of the nodal zone capacities and other necessary data are given in Table 4. Again comparison with the corresponding compressive force in struts confirms that the capacities of all the nodal zones are adequate.

\subsection{Main steel reinforcement and layout}

For the tie member 3-8 to be able to carry a tensile force of $46.4 \mathrm{kN}$, the required crosssectional area of steel reinforcement is $A_{s t}=F^{*} / \phi f_{y}=46.4 \times 10^{3} /(0.75 \times 400)=154.7 \mathrm{~mm}^{2}$ when Y400 steel is used. This suggests that either 1 Y16 bar $\left(200 \mathrm{~mm}^{2}\right)$ or 2 Y12 bars $\left(220 \mathrm{~mm}^{2}\right)$ can be selected for tie 3-8. The tensile force of member $1-3(38.8 \mathrm{kN})$ is smaller than that of 3-8, hence 2 Y12 bars can also be employed.

Members 2-5 and 5-7 also require steel reinforcement. The cross-sectional area of steel is $A_{s t}=F^{*} / \phi f_{y}=14.3 \times 10^{3} /(0.75 \times 400)=47.7 \mathrm{~mm}^{2}$ and hence only $1 \mathrm{Y} 12$ bar $\left(110 \mathrm{~mm}^{2}\right)$ is required. The layout of main steel reinforcement in deep beam O-0.3/16 is illustrated in Figure 5. Note that the anchorage length is not adequate based on the clause 8.2.12.4 of AS3600 (2002), $180^{\circ}$ standard hooks are therefore recommended as detailed also in Figure 5.

\section{Conclusion}

In this paper, topology optimisation method with stress and displacement constraints is employed with the aim of maximising the material efficiency and overall stiffness of deep 
beams. The method is used successfully to automatically produce the strut-and-tie models for a total of 14 concrete deep beams with varying size and location of web openings. The resulting optimal topology (strut-and-tie model) is a fully stressed design and accurately represents the actual stress path and the load transfer mechanism. The developmental history of a representative strut-and-tie model is presented and its correctness is supported by the experimental evidence. A series of comparison has provided insight into various parameters that affect the load transfer mechanism and the ultimate shear strength of concrete deep beams.

It should be noted that the strut-and-tie models provides only the locations of struts, ties and nodes for a structural deep beam. Dimensioning the struts, ties and nodes should be based on the strength performance criteria specified in the design codes. To demonstrate the effectiveness of the resulting strut-and-tie model in aiding the design of deep beams, a worked design example of a representative beam is also presented. The bearing capacities of the loading point and support as well as the capacities of the struts and nodal zones are checked according to ACI 318-05. The amount, layout arrangement and anchorage of steel reinforcement are also determined to closely follow the strut-and-tie model.

The study has demonstrated that the design of deep beams with web openings can be efficiently conducted by developing strut-and-tie models using the topology optimisation approach. A safe and economical design in terms of overall structural performance can be achieved and the time-consuming task to develop truss models using conventional methods can be avoided. 


\section{Acknowledgments}

The assistance of a former graduate student Miss Sunita Eurviriyanukul in analysing some of the numerical models is gratefully acknowledged.

\section{References}

Ali, M. and White, R.N. (2001). “Automatic generation of truss model for optimal design of reinforced concrete structures”, ACI Structural Journal, Vol. 98, No. 4, pp. 431-442.

Almeida, A. and Pinto, N. (1999). "High strength concrete deep beams with web openings", ACI Special Publications, SP-1, No. 186, pp. 567-613.

American Concrete Institute (ACI) (2002). Building Code Requirements for Structural Concrete (ACI 318-02) and Commentary - ACI318R-02, Detroit, Michigan.

American Concrete Institute (ACI) (2005). Building Code Requirements for Structural Concrete (ACI 318-05) and Commentary - ACI318R-05, Detroit, Michigan.

Ashour, A. and Rishi, G. (2000). “Tests of reinforced concrete continuous deep beams with web openings”, ACI Structural Journal, Vol. 97, No. 3, pp. 418-426.

Biondini, F., Bontempi, F. and Malerba, P.G. (2001). "Stress path adapting strut-and-tie models in cracked and uncracked R.C. elements”, Structural Engineering and Mechanics, Vol. 12, No. 6, pp. 685-698.

Canadian Standard Association (1994). Design of Concrete Structures, Standard (CSA-A23.394). Ontario, Canada.

CIRIA (1997). CIRIA Guide 2: The Design of Deep Beams in Reinforced Concrete. London, UK. 
Guan, H. (2005). "Strut-and-tie model of deep beams with web openings - an optimisation approach", Structural Engineering and Mechanics - An International Journal, Vol. 19, No. 4, pp. 361-379.

Kong, F.K. (1990). Reinforced Concrete Deep Beams, Blackie and Sons, Glasgow, UK.

Kong, F.K. and Sharp, G.R. (1977). "Structural idealization for deep beams with web openings”, Magazine of Concrete Research, Vol. 29, No. 99, pp. 81-91.

Kong, F.K., Sharp, G.R., Appleton, S.C., Beaumont, C.J. and Kubik, L.A. (1978). “Structural idealization for deep beams with web openings: further evidence”, Magazine of Concrete Research, Vol. 30, No. 103, pp. 89-95.

Liang, Q.Q. (2005). Performance-based Optimization of Structures: Theory and applications. Spon Press, London.

Liang, Q.Q., Xie, Y.M. and Steven, G.P. (2000). “Topology optimisation of strut and tie model in reinforced concrete structures using an evolutionary procedure”, ACI Structural Journal, Vol. 97, No. 2, pp. 322-330.

Mansur, M.A. and Alwis, W.A.M. (1984). "Reinforced fibre concrete deep beams with web openings”, International Journal of Cement Composites and Lightweight Concrete, Vol. 6, No. 4, pp. 263-271.

Maxwell, B. and Breen, J. (2000). "Experimental evaluation of strut and tie model applied to deep beam with opening”, ACI Structural Journal, Vol. 97, No. 1, pp. 142-148.

Ray, D. P. (1990). “Deep beam with web openings”, In: Kong, F. K., Reinforced Concrete Deep Beams, Van Nostrand Reinhold, New York, pp. 60-94.

Reynolds, D., Christie, W.C., Bettess, P., McConnachie, J. and Bull, J.W. (2001). "Evolutionary material translation: a tool for the automatic design of low weight, low stress structures”, International Journal for Numerical Methods in Engineering, Vol. 50, pp. 147-167. 
Siao, W.B. (1995). “Deep Beams Revisited”, ACI Structural Journal, Vol. 92, No. 1, pp. 95102.

Standards Association of Australia (SAA) (2002). AS3600-2002: Concrete Structures, Sydney, Australia.

Tan, K.H., Tong, K. and Tang, C.Y. (2003). “Consistent strut-and-tie modelling of deep beams with web openings”, Magazine of Concrete Research, Vol. 55, No. 1, pp. 65-75.

Xie, Y.M. and Steven, G.P. (1997). Evolutionary Structural Optimisation, Springer-Verlag, London, UK. 


\section{Table Legends}

Table 1. Strut-and-tie models influenced by the size of web openings

Table 2. Strut-and-tie models influenced by the location of web openings

Table 3. Summary of strut capacity for O-0.3/16

Table 4. Summary of nodal zone capacity for O-0.3/16 


\section{Figure Captions}

Figure 1. Simply supported deep beam under two concentrated loads (symmetrical half)

Figure 2. Optimisation of deep beam O-0.3/16

Figure 3. Forces in struts and ties for $\mathrm{O}-0.3 / 16$

Figure 4. Flow chart of design procedure

Figure 5. Layout of main steel reinforcement in O-0.3/16 (dimensions: mm) 


\section{Notation}

\begin{tabular}{|c|c|c|}
\hline$a_{1}, a_{2}$ & $=$ & Coefficients defining the dimensions of an opening \\
\hline$A_{c}$ & $=$ & Cross-sectional area at one end of a strut \\
\hline$A_{n}$ & $=$ & Area of nodal zone face \\
\hline$A_{s t}$ & $=$ & Total cross-sectional area of reinforcing bars \\
\hline$b$ & $=$ & Breath of deep beam \\
\hline$d_{a}$ & $=$ & Depth of strut or anchored depth of a tie \\
\hline$D, L$ & $=$ & Depth and span of deep beam, respectively \\
\hline$d_{\text {strut }}$ & $=$ & Depth of strut between two nodal zones \\
\hline E & $=$ & Young's modulus of concrete \\
\hline$E R$ & $=$ & Evolution rate \\
\hline$F^{*}$ & $=$ & Design force in a strut or tie \\
\hline$F_{u n}$ & $=$ & Nominal compressive strength of a nodal zone \\
\hline$F_{u s}$ & $=$ & Nominal compressive strength of a strut \\
\hline$f_{c}^{\prime}$ & $=$ & Compressive cylinder strength of concrete at 28 days \\
\hline$f_{c u}$ & $=$ & Effective compressive strength of concrete in strut or nodal zone \\
\hline$f_{y}$ & $=$ & Yield strength of steel reinforcement \\
\hline$k_{1}, k_{2}$ & $=$ & Coefficients defining the position of a web opening \\
\hline $\boldsymbol{K}_{i}$ & $=$ & Stiffness matrix of $i^{\text {th }}$ element \\
\hline$L$ & $=$ & Total number of load cases \\
\hline$l_{b}$ & $=$ & Width of bearing plate \\
\hline$M$ & $=$ & Total number of displacement constraints \\
\hline$N$ & $=$ & Total number of elements in design domain \\
\hline$N_{d}$ & $=$ & Number of elements with lowest displacement sensitivity number \\
\hline
\end{tabular}




\begin{tabular}{|c|c|c|}
\hline$N_{s}$ & $=$ & Number of identified lowly stressed elements \\
\hline$P I_{d}$ & $=$ & Performance index in terms of nodal displacement \\
\hline$P I_{V M}$ & $=$ & Performance index in terms of von Mises stress \\
\hline$R R_{i}$ & $=$ & Rejection ratio at $i^{\text {th }}$ iteration \\
\hline$u_{j}^{*}$ & $=$ & Prescribed displacement limit \\
\hline $\boldsymbol{u}_{i k}, \boldsymbol{u}_{i j}$ & $=$ & $\begin{array}{l}\text { Displacement vectors of } i^{\text {th }} \text { element due to real load case } k \text { and virtual } \\
\text { unit load at node } j\end{array}$ \\
\hline$u_{o}, u_{j}$ & $=$ & Nodal displacement at constrained location at initial and $i^{\text {th }}$ iteration \\
\hline$V_{o}, V_{i}$ & $=$ & Volume of design domain at initial and $i^{\text {th }}$ iteration \\
\hline$x$ & $=$ & Clear shear span distance \\
\hline$\alpha_{d, i}$ & $=$ & Displacement sensitivity number \\
\hline$\beta_{n}$ & $=$ & Factor reflecting the degree of disruption of a nodal zone \\
\hline$\beta_{s}$ & $=$ & Factor reflecting the degree of disruption of a strut \\
\hline$\phi$ & $=$ & Strength reduction factor \\
\hline$\phi, \phi^{\prime}$ & $=$ & Angles defining the directions of potential critical diagonal cracks \\
\hline$\lambda_{j k}$ & $=$ & Weighting parameter \\
\hline$v$ & $=$ & Poisson’s ratio \\
\hline$\sigma_{v M}^{e}$ & $=$ & von Mises stress of an element \\
\hline$\sigma_{v M, \max }$ & $=$ & Maximum von Mises stress of the model \\
\hline$\theta$ & $=$ & Inclination angle of a strut \\
\hline
\end{tabular}




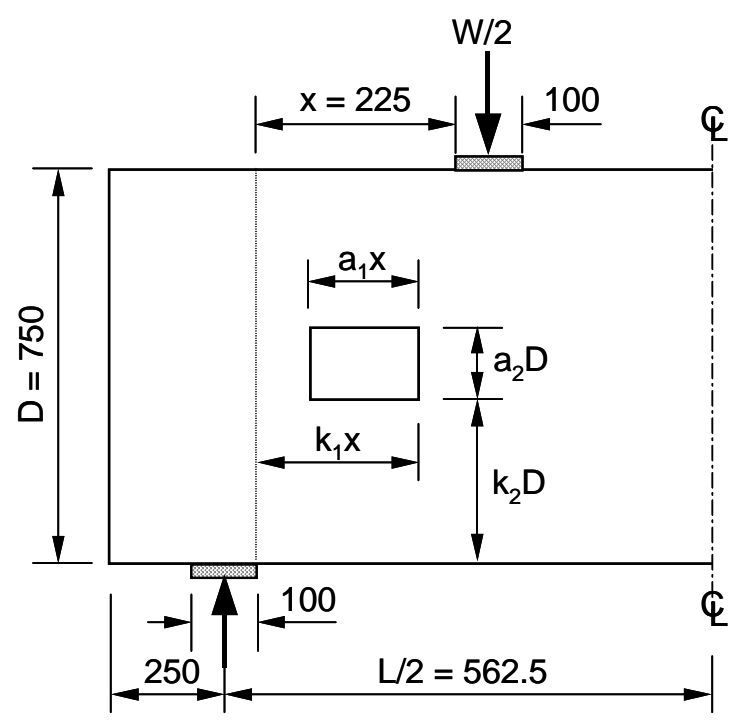

(a) Size and location of web opening (dimensions: $\mathrm{mm}$ )

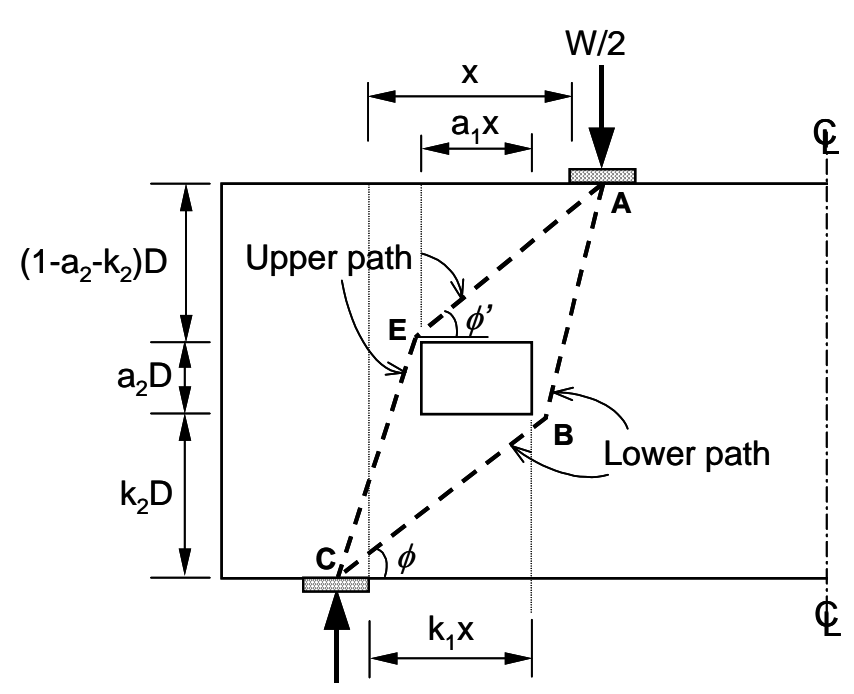

(b) Structural idealisation

Figure 1. Simply supported deep beam under two concentrated loads (symmetrical half) 


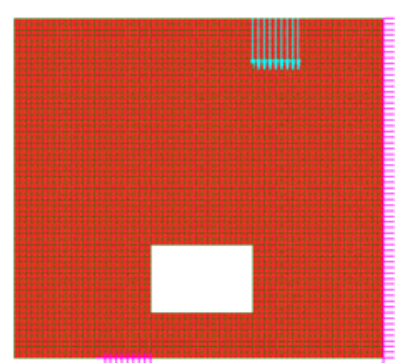

(a) Original topology

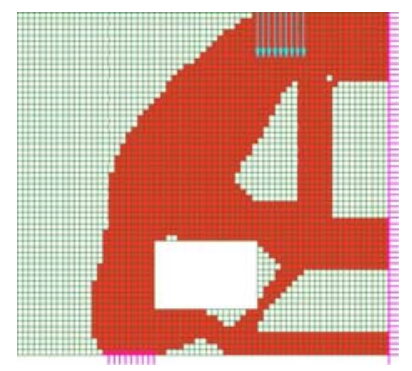

(c) Topology at 50\% volume reduction

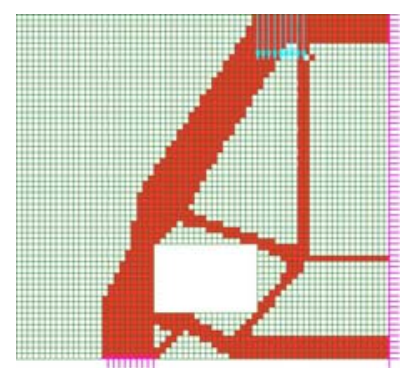

(e) Optimal topology

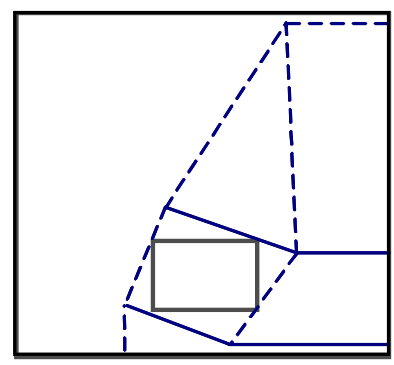

(g) Strut-and-tie model

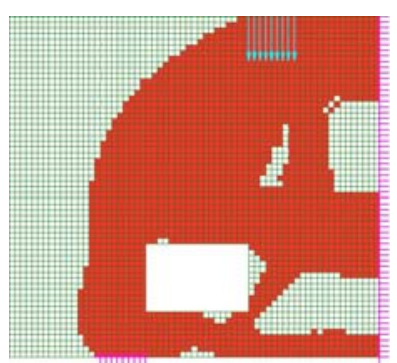

(b) Topology at $40 \%$ volume reduction

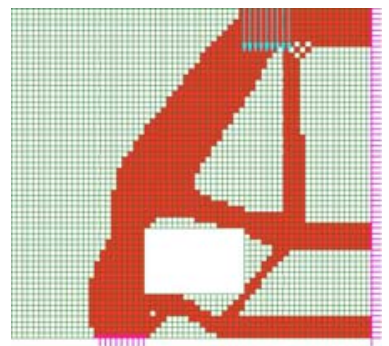

(d) Topology at $60 \%$ volume reduction

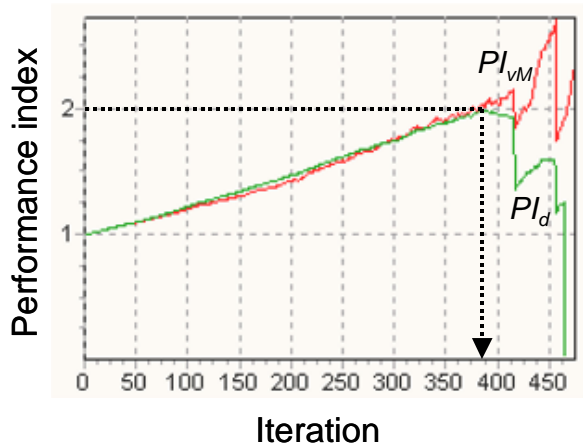

(f) Performance indices

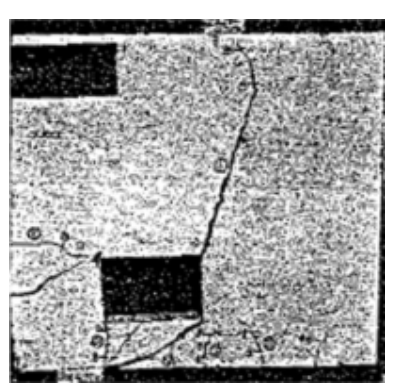

(h) Crack Pattern

Figure 2. Optimisation of deep beam O-0.3/16 


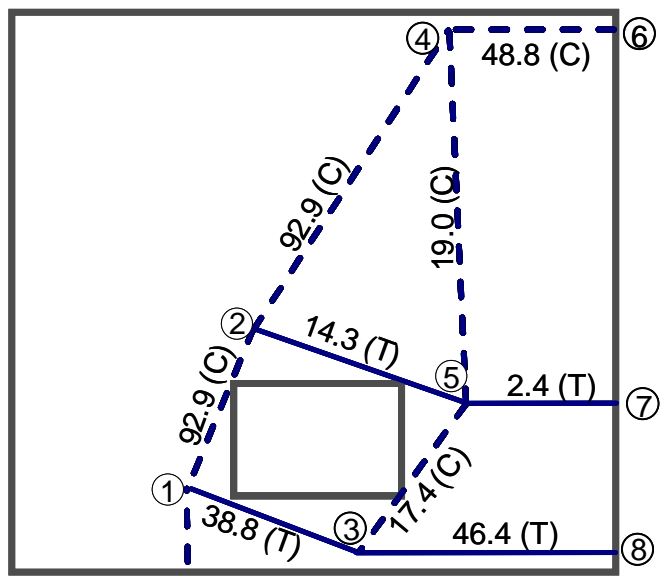

Figure 3. Forces in struts and ties for O-0.3/16 


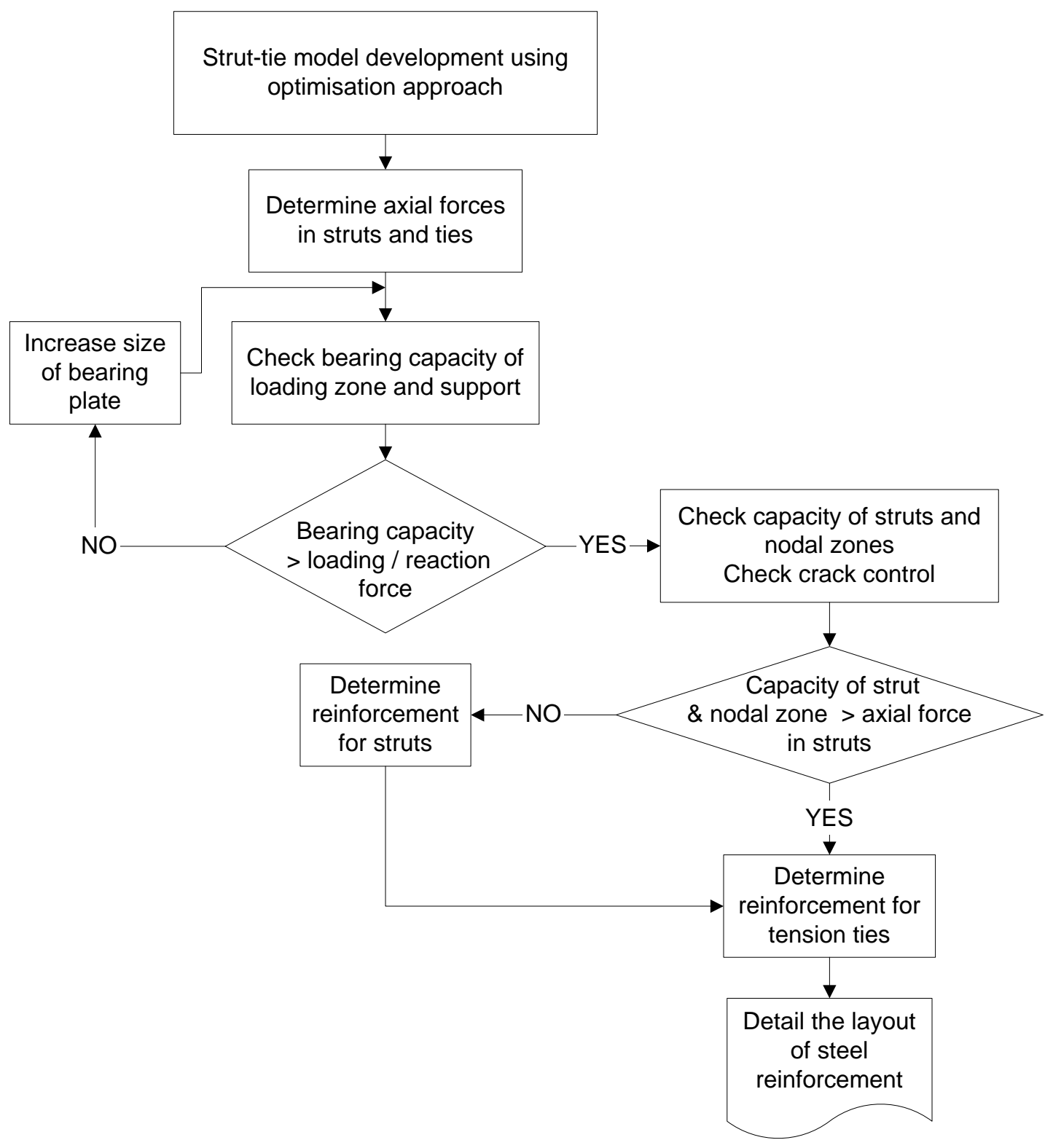

Figure 4. Flow chart of design procedure 


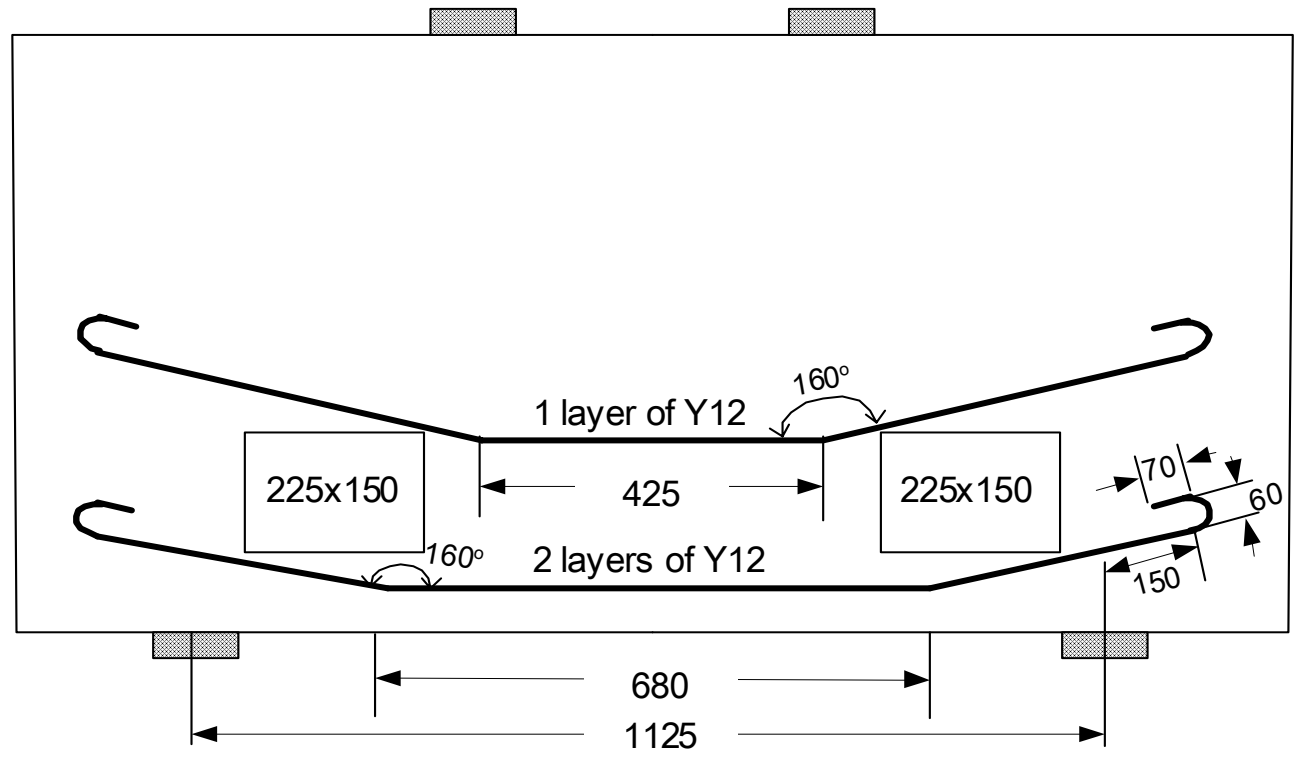

Figure 5. Layout of main steel reinforcement in O-0.3/16 (dimensions: mm) 
Table 1. Strut-and-tie models influenced by the size of web openings

(a)

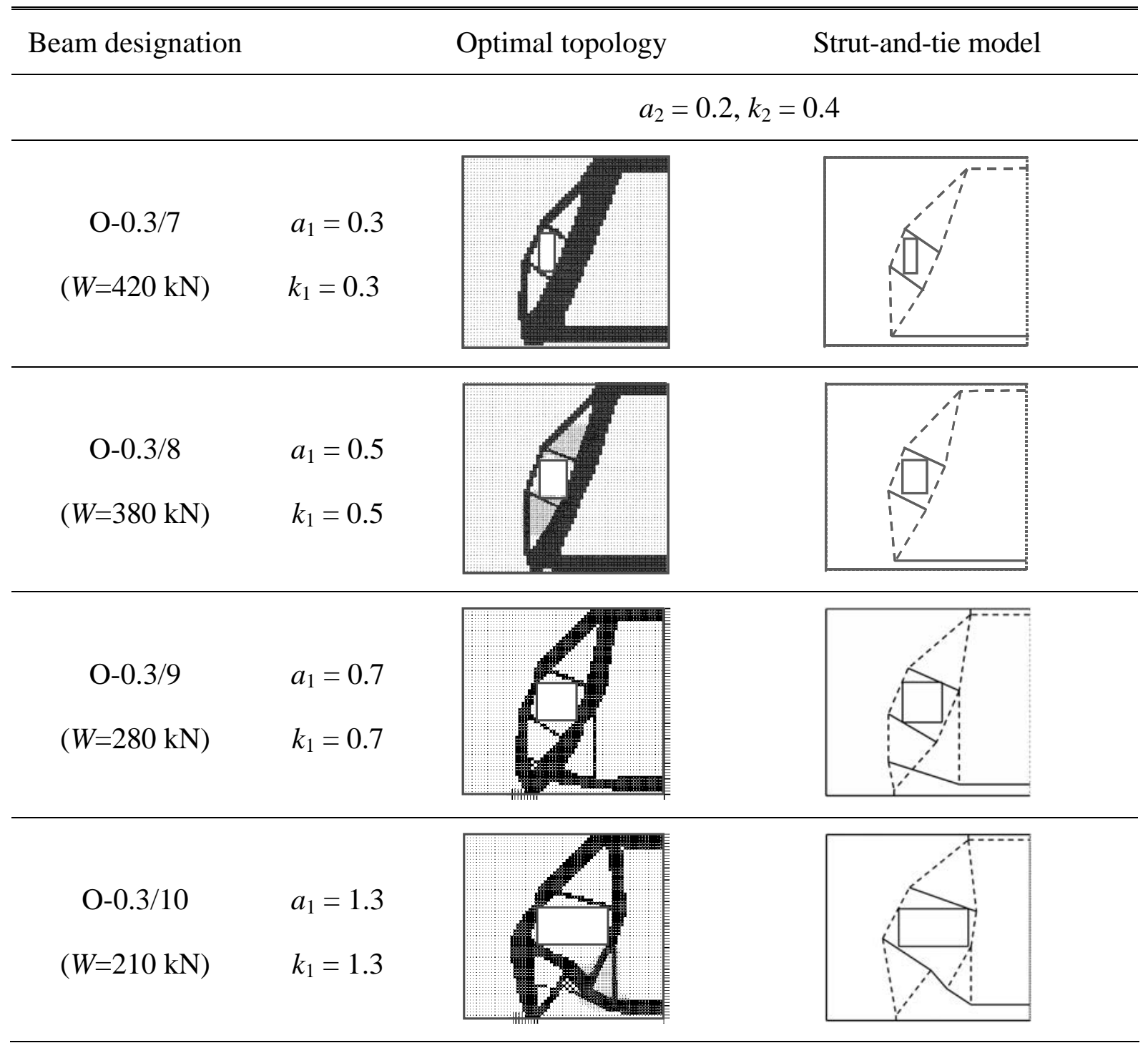


(b)

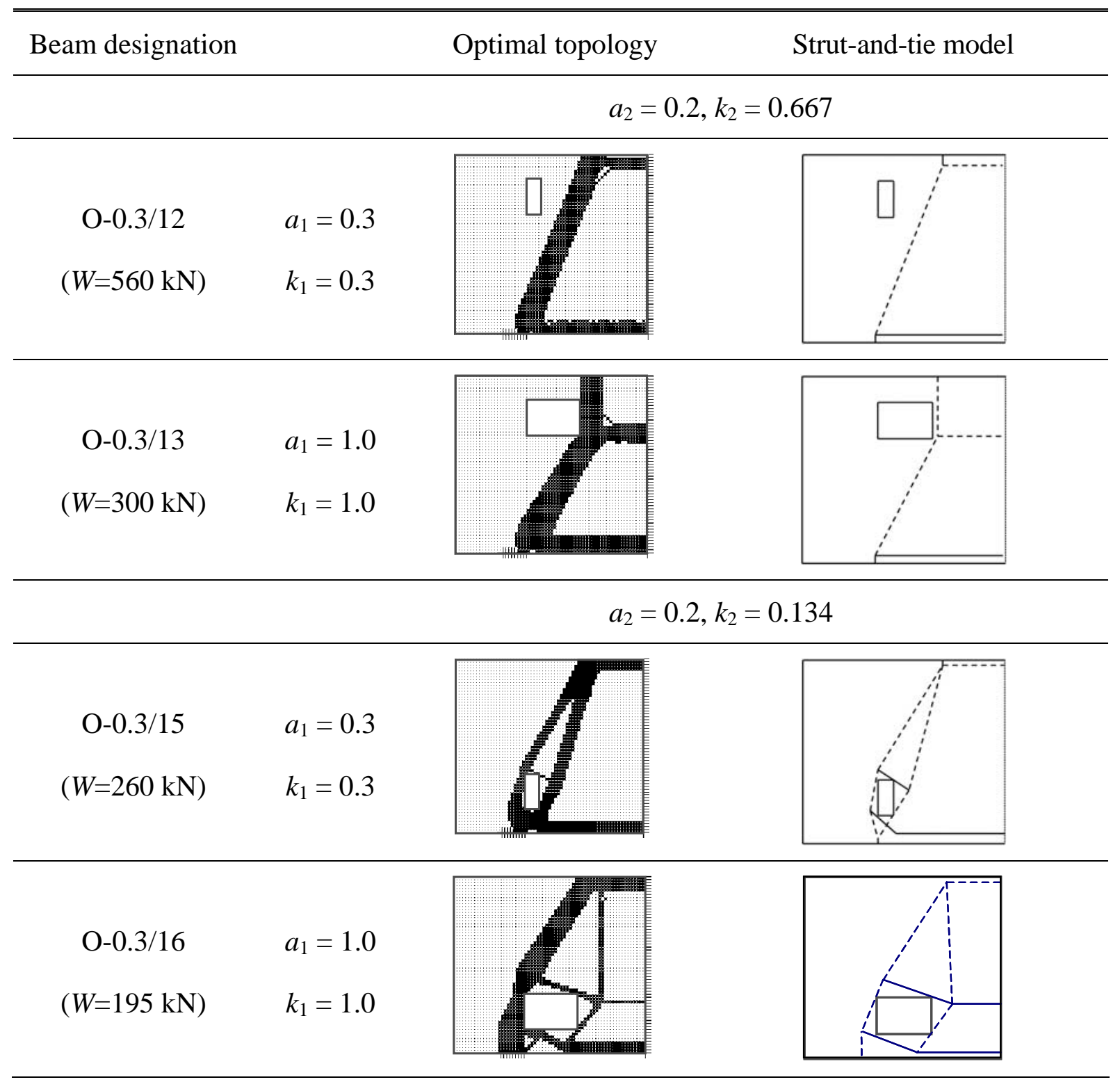

Note: (1) O - beam without web reinforcement; 0.3 - $x / D$ ratio; /number - web opening reference number (Kong and Sharp 1977).

(2) $W$ - ultimate shear strength (Kong and Sharp 1977).

(3) Solid lines - tension ties; dash lines - compression struts. 
Table 2. Strut-and-tie models influenced by the location of web openings

(a)

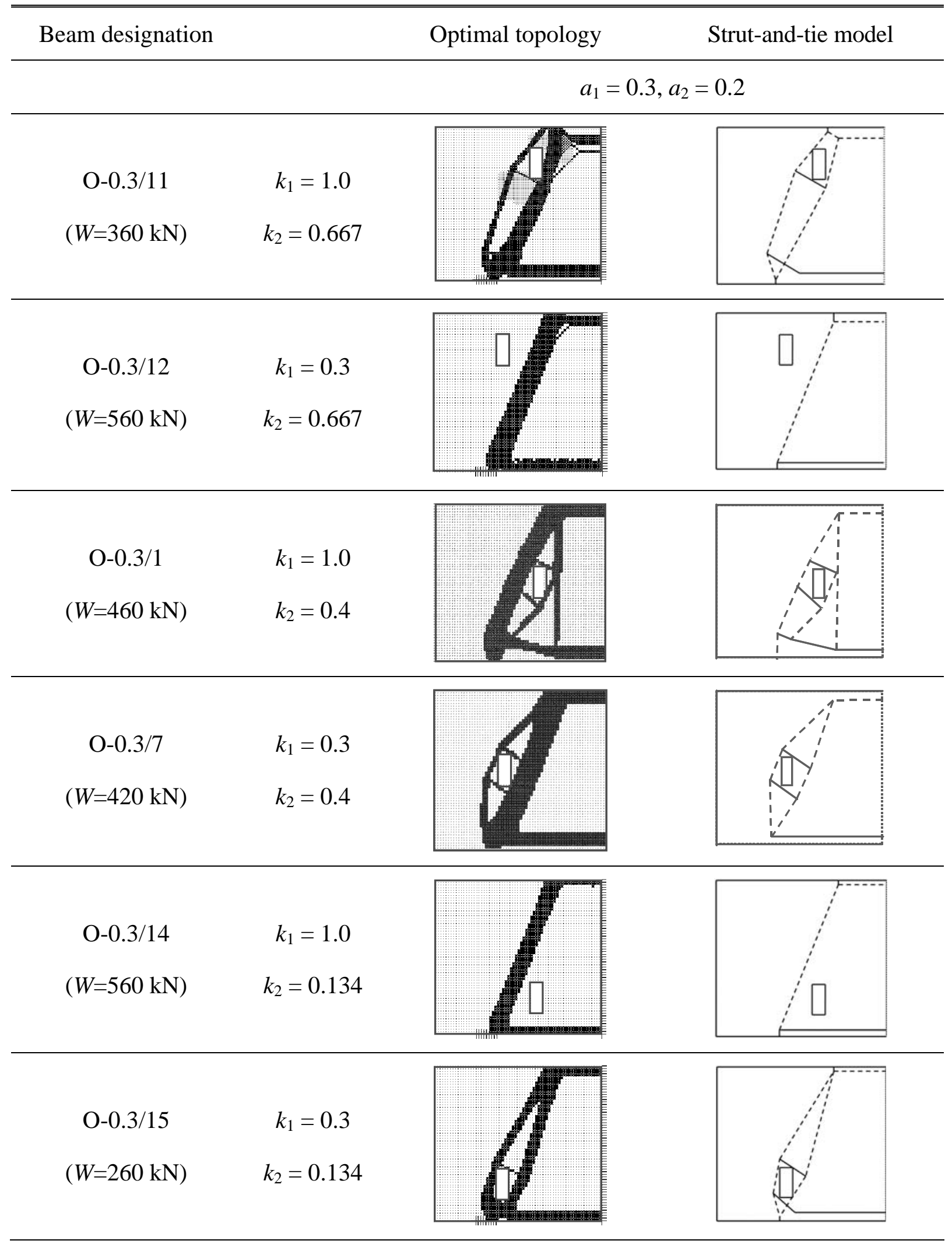


(b)

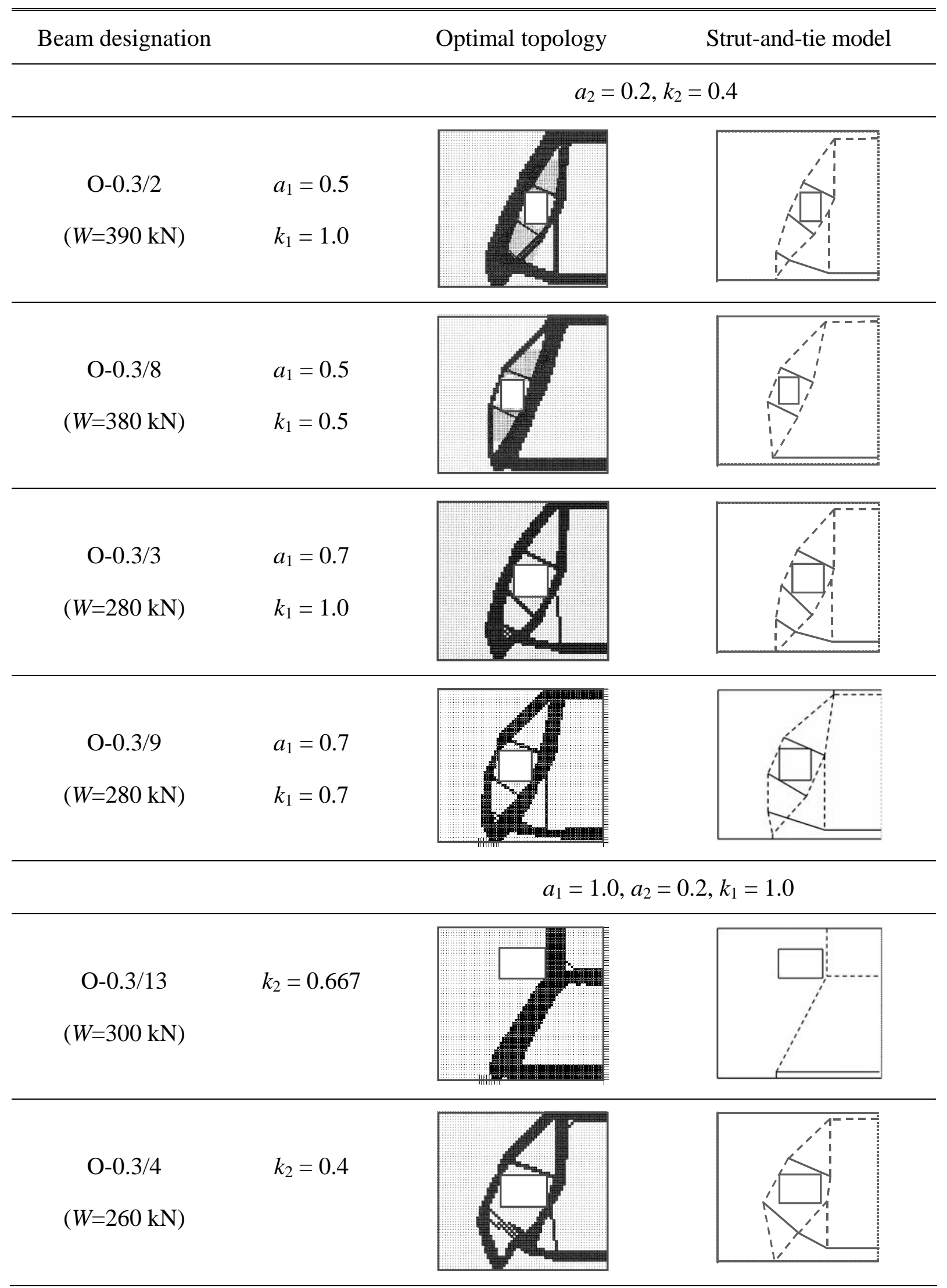


$(W=195 \mathrm{kN})$
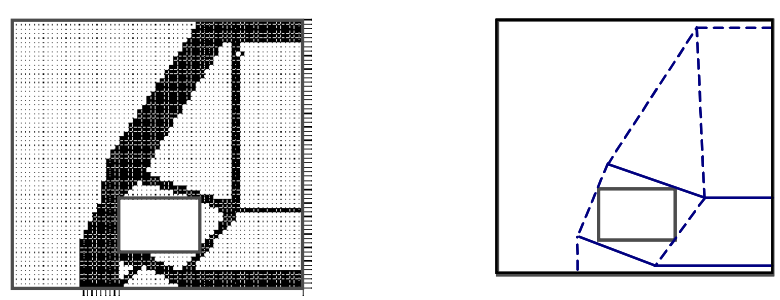
Table 3. Summary of strut capacity for O-0.3/16

\begin{tabular}{|c|c|c|c|c|c|c|c|c|c|}
\hline Strut & Characteristics & $\beta_{s}$ & $\begin{array}{c}l_{b} \\
(\mathrm{~mm})\end{array}$ & $\begin{array}{c}d_{a} \\
(\mathrm{~mm})\end{array}$ & $\begin{array}{l}\theta \\
\left({ }^{\circ}\right)\end{array}$ & $\begin{array}{l}d_{\text {strut }} \\
(\mathrm{mm})\end{array}$ & $\begin{array}{c}\text { Capacity } \\
\phi F_{u s} \\
(\mathrm{kN})\end{array}$ & & $\begin{array}{c}\text { Compressive } \\
\text { force } \\
(\mathrm{kN})\end{array}$ \\
\hline $1-2$ & $\begin{array}{l}\text { Bottle-shaped strut } \\
\text { without crack control }\end{array}$ & 0.6 & 100 & 50 & 66.5 & 111.6 & 160.6 & $>$ & 92.9 \\
\hline $2-4$ & $\begin{array}{l}\text { Bottle-shaped strut } \\
\text { without crack control }\end{array}$ & 0.6 & 100 & 50 & 57.9 & 111.3 & 160.0 & $>$ & 92.9 \\
\hline $3-5$ & $\begin{array}{l}\text { Bottle-shaped strut } \\
\text { without crack control }\end{array}$ & 0.6 & 100 & 50 & 53.8 & 110.24 & 158.5 & $>$ & 17.4 \\
\hline $5-4$ & $\begin{array}{c}\text { Bottle-shaped strut } \\
\text { without crack control }\end{array}$ & 0.6 & 100 & 50 & 92.5 & 97.7 & 140.5 & $>$ & 19.0 \\
\hline $4-6$ & $\begin{array}{c}\text { Strut in compression } \\
\text { zone }\end{array}$ & 1 & 100 & 50 & 0 & 50 & 140.5 & $>$ & 48.8 \\
\hline
\end{tabular}


Table 4. Summary of nodal zone capacity for O-0.3/16

\begin{tabular}{cccccc}
\hline $\begin{array}{c}\text { Nodal } \\
\text { zone }\end{array}$ & Characteristics & $\beta_{n}$ & $\begin{array}{c}\text { Capacity } \\
\phi F_{u n} \\
(\mathrm{kN})\end{array}$ & $\begin{array}{c}\text { Compressive } \\
\text { force } \\
(\mathrm{kN})\end{array}$ \\
\hline 1 & Anchors one tie & 0.8 & 191.8 & $>$ & 92.9 \\
\hline 2 & Anchors one tie & 0.8 & 191.8 & $>$ & 92.9 \\
\hline 3 & Anchors two ties & 0.6 & 143.8 & $>$ & 17.4 \\
\hline 5 & Anchors two ties & 0.6 & 143.8 & $>$ & 19.0 \\
\hline 4 & Bounded by bearing area & 1 & 239.7 & $>$ & 97.5 \\
\hline
\end{tabular}

